\title{
Influência do agente clareador peróxido de carbamida a $10 \%$ na resistência mecânica da colagem de braquetes ortodônticos
}

\author{
Edgard Norões R. da Matta*, José de Albuquerque Calasans Maia**, Orlando Chevitarese ${ }^{\star \star \star}$
}

\begin{abstract}
Resumo
O propósito deste estudo in vitro foi determinar a influência do agente clareador peróxido de carbamida a $10 \%$ na resistência mecânica da colagem de braquetes ortodônticos. Foram estudados três grupos denominados G1 (não submetido ao clareamento), G2 (com clareamento e colagem realizada 1 semana após) e G3 (com clareamento e colagem realizada 24h após). O teste de cisalhamento foi conduzido na máquina de ensaios mecânicos Emic, com a velocidade de deformação de $0,5 \mathrm{~mm} / \mathrm{min}$. A resitência ao cisalhamento em relação à área de colagem foi calculada para cada dente e expressa em $\mathrm{MPa}$. Os resultados mostraram aumento estatisticamente significante $(\mathrm{p}<0,001)$ da resistência mecânica da colagem após clareamento.
\end{abstract}

Palavras-chave: Clareamento dentário. Peróxido de carbamida. Resistência da colagem.

\section{INTRODUÇÃO}

A estética, na atualidade, é indubitavelmente uma exigência dos pacientes que procuram o consultório odontológico para modificarem ângulos, posições dentárias e a cor dos dentes ${ }^{1}$.

O clareamento dentário é o tratamento estético mais popular na Odontologia com o objetivo da modificação da cor do dente ${ }^{5}$ e o peróxido de carbamida é o agente clareador mais utilizado para o tratamento do manchamento intrínseco de dentes hígidos que apresentam ou não o tratamento endodôntico, pela sua ação na superfície do esmalte, tendo diversas concentrações e tempos de aplicação $0^{7,14}$.

A influência dos procedimentos de clareamento na resistência mecânica da colagem de braquetes à superfície dentária foi investigada por Bishara, Sulieman e Olson ${ }^{2}$, tendo constatado que o processo de clareamento com peróxido de carbamida a $10 \%$ não interfere na resistência adesiva do esmalte dentário. Entretanto, Miles, Pontier, Bahirael et al. ${ }^{8}$ afirmam que há alteração na resistência mecânica da colagem do esmalte submetido ao procedimento de clareamento, onde possivelmente o resíduo do material clareador interfere junto ao compósito, impedindo ou alterando a formação dos tags, diminuindo desta forma a resistência mecânica da colagem. No entanto, Torneck, Tytley, Smith e Adibfar ${ }^{11}$ relatam aumento da adesividade da resina ao esmalte quando submetido ao clareamento.

* Professor assistente da Disciplina de Ortodontia da UFAL. Mestre em Ortodontia pela Faculdade de Odontologia da UFRJ. Doutorando em Ortodontia pela Faculdade de Odontologia da UFRJ.

** Coordenador do Curso de Especialização em Ortodontia da UGF. Mestre em Ortodontia pela Faculdade de Odontologia da UFRJ. Doutorando em Ortodontia pela Faculdade de Odontologia da UFRJ.

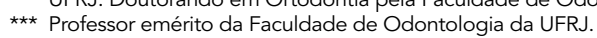


A procura de tratamento ortodôntico após a realização de procedimento de clareamento dos dentes, leva o ortodontista a questionar a influência deste agente clareador nos procedimentos de colagem e descolagem do braquete ao esmalte dentário. Esta é a razão deste trabalho que pretende avaliar a influência do processo de clareamento com peróxido de carbamida a 10\% sobre a resistência adesiva do esmalte.

\section{MATERIAL E MÉTODO}

Quarenta e dois dentes bovinos, recém-extraídos, foram armazenados em solução aquosa de Timol a $1 \%$. Iniciando o preparo dos dentes para colagem, cada elemento dentário teve sua face vestibular marcada com um ponto feito com lápis preto em sua porção central, exatamente no local onde o braquete deveria ser colado. Cada dente teve sua coroa incluída em resina acrílica autopolimerizável, sobre uma placa de vidro, de modo que a área marcada pudesse ser pressionada contra a placa

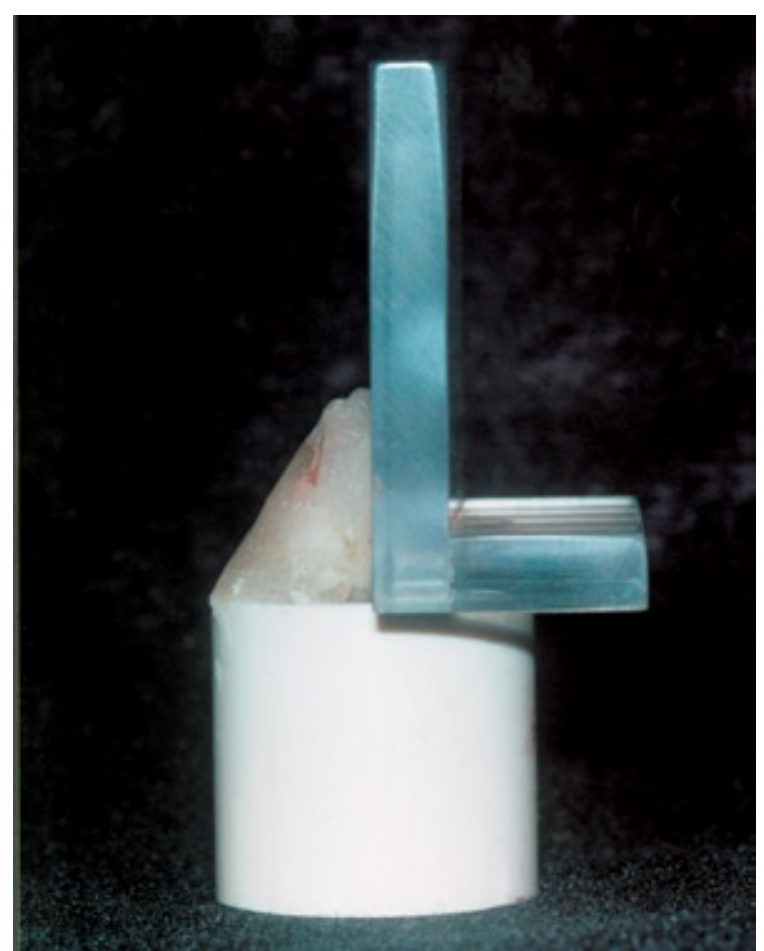

FIGURA 1 - Visão lateral da colocação do dente bovino no tubo de PVC com auxílio do esquadro-guia. até tocá-la, enquanto a superfície da placa ficou em posição aproximadamente paralela ao eixo da coroa. Com tal disposição, conseguiu-se a obtenção de uma área plana, tendo obtido assim uma superfície plana resina/dente.

A seguir, a área foi lixada (lixa d'água $n^{\circ} 100$ ) até a obtenção de uma superfície suficientemente larga para receber um braquete ortodôntico, seguindo-se lixa $n^{\circ} 600$, para o alisamento final de modo a conseguir-se praticamente a mesma profundidade do desgaste no esmalte.

A seguir, cada dente teve sua raiz incluída em resina acrílica autopolimerizável contida em um anel de PVC de bases perpendiculares ao seu eixo, de tal forma que a superfície planificada da coroa estivesse em $90^{\circ} \mathrm{com}$ as bases, o que se conseguiu por meio de um esquadro-guia de acrílico preparado para este fim (Fig. 1, 2).

Após a polimerização da resina acrílica autopolimerizável, todos os corpos de prova foram estocados em água à temperatura ambiente.

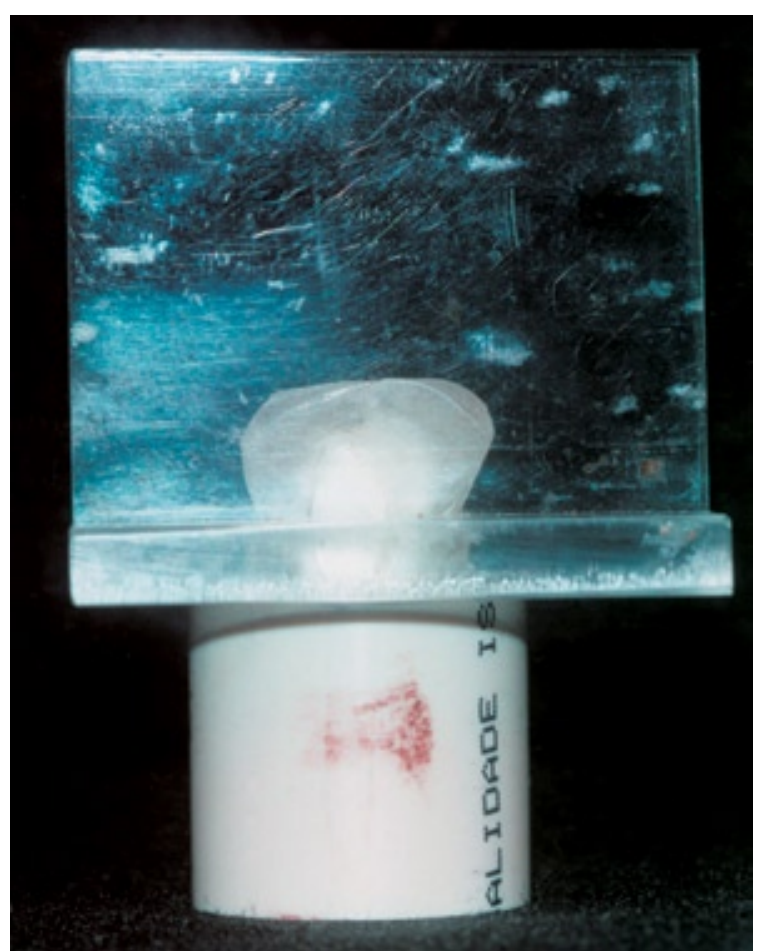

FIGURA 2 - Visão frontal da colocação do dente bovino no tubo de PVC com auxílio do esquadro-guia. 
Os incisivos bovinos foram divididos em 3 grupos de 14 dentes. O Grupo I (G1) incluiu os dentes que não se submeteram ao clareamento. O Grupo II (G2) constitui-se de 14 dentes que foram submetidos a 1 semana de clareamento e, após, armazenados em água a $36 \pm 1{ }^{\circ} \mathrm{C}$ e, após 1 semana, foi executada a colagem. Já o Grupo III (G3) foi composto de 14 dentes que também foram submetidos a 1 semana de clareamento, porém a colagem foi executada após 24 horas, armazenados em água a $36 \pm 1^{\circ} \mathrm{C}$, após finalizado o clareamento.

O clareamento foi executado com peróxido de carbamida a $10 \%$ da marca comercial Whitheness fabricado por FGM Produtos Odontológicos. Sobre cada superfície de esmalte correspondente à área da futura colagem foi colocada uma máscara de fita adesiva plástica, com espessura total correspondente a 6 vezes a sua espessura individual com perfuração central de $6 \mathrm{~mm}$ de diâmetro, simulando dessa forma uma moldeira com alívio suficiente para o depósito do material clareador. Por sobre essa moldeira colocou-se um segmento de fita protegendo e selando o material clareador para que o mesmo não seja diluído em água (Fig. 3).

O tempo estipulado para o clareamento foi de

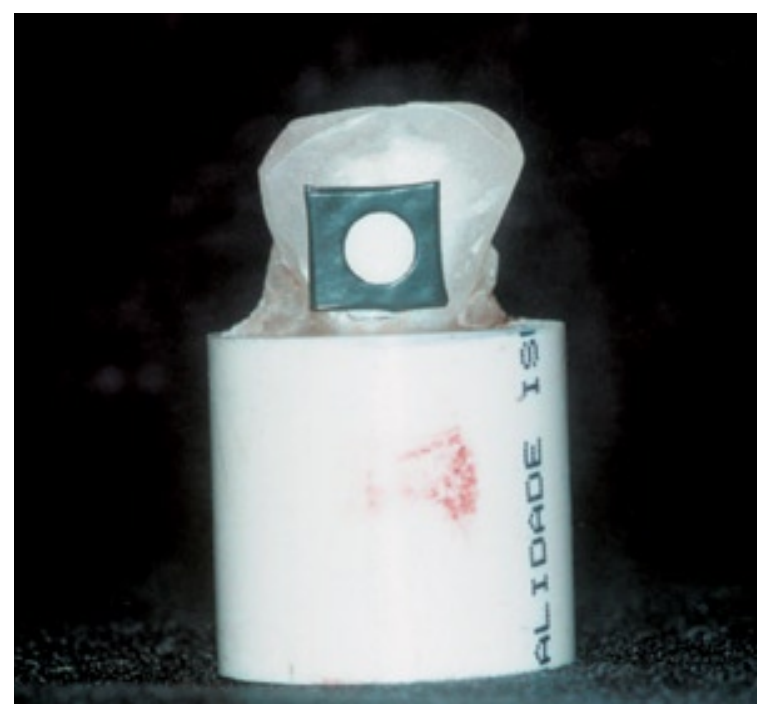

FIGURA 3 - Máscara de fita adesiva simulando moldeira individual para colocação do clareador.
10 dias, com aplicação de 4 horas diárias conforme recomendações do fabricante, imersos em água e mantidos em estufa à temperatura de $36 \pm 1{ }^{\circ} \mathrm{C}$. Após o tempo estipulado para o clareamento, a solução clareadora, bem como a máscara de fita adesiva foram removidas e os dentes imersos em água mantidos em estufa à temperatura de $36 \pm 1^{\circ} \mathrm{C}$, simulando a temperatura corpórea.

O polimento das superfícies dentárias, foi realizado em um único dia e compreendeu: profilaxia com pasta de pedra pomes e água em taça de borracha à baixa rotação por 10 segundos, lavagem com água e ar por 15 segundos e secagem com jato de ar na seringa tríplice por 10 segundos. Visando tornar o desgaste do esmalte oriundo da profilaxia, o mais homogêneo possível, a taça de borracha foi trocada por outra nova a cada 5 profilaxias executadas.

Procedeu-se ao condicionamento ácido por 15 segundos com ácido ortofosfórico a $37 \%$ sob a forma de gel e em seguida, à lavagem da superfície condicionada por 15 segundos e à secagem por 10 segundos.

Os braquetes foram colados nas áreas delimitadas com auxílio de um esquadro guia que contem um fio retangular, de forma que o slot esteja em posição vertical e perpendicular à base do anel de PVC.

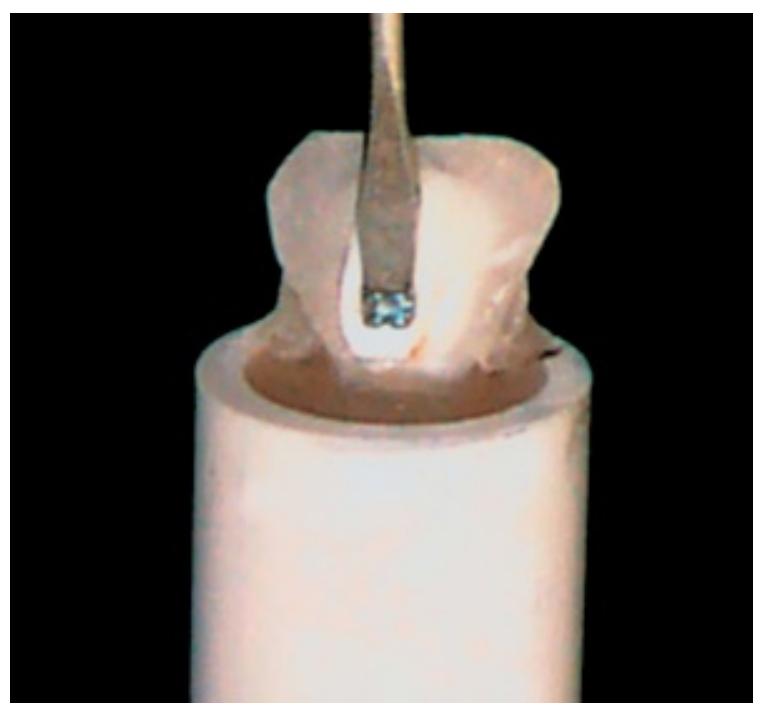

FIGURA 4 - Remoção do acessório com ponta ativa da máquina de ensaios de cisalhamento Emic. 
A manipulação do compósito seguiu rigorosamente as instruções do fabricante, sendo pressionado contra a base do braquete e após esta etapa o braquetefoi levado ao esmalte com o auxílio do esquadro, onde o mesmo estará previamente fixado.

Passados 30 minutos de polimerização do compósito, cada grupo de dentes foi estocado em água à temperatura de $36^{\circ} \pm 1^{\circ} \mathrm{C}$ em estufa durante 14 dias. Ao final deste período, os dentes foram submetidos ao ensaio mecânico de cisalhamento, executado em uma máquina EMIC, com a velocidade de deformação de $0,5 \mathrm{~mm}$ por minuto (Fig. 4). As cargas de ruptura foram registradas em papel milimetrado por uma impressora acoplada à máquina, em MPa (Mega Pascal). Para o cálculo da resistência ao cisalhamento dividiu-se o valor da força de descola-

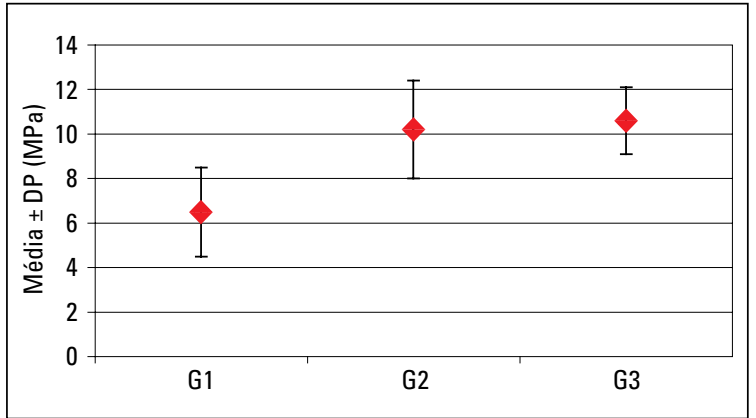

Gráfico 1 - Valores médios e desvios-padrão da resistência (MPa) entre os grupos estudados. gem fornecida pela máquina de ensaios mecânicos pelo valor da área de superfície da base do braquete em $\mathrm{cm}^{2}$. Os dados foram analisados estatisticamente e as comparações executadas.

\section{RESULTADOS E DISCUSSÃO}

A busca de tratamento odontológico com objetivos cosméticos tem levado o ortodontista a investigar a influência dos agentes clareadores na resistência mecânica da colagem de braquete ortodônticos, já que esses profissionais enfrentam situações clínicas em que o paciente foi submetido a tratamento clareador imediatamente antes da execução do tratamento ortodôntico.

$\mathrm{Na}$ tabela 1 encontram-se os resultados da estatística descritiva, onde constam os valores médios, desvio-padrão, valores mínimos e máximos da resistência ao cisalhamento (em $\mathrm{MPa}$ ) dos três grupos, bem como também os resultados do tratamento estatístico.

Os valores médios apresentados na tabela acima evidenciam a influência do agente clareador peróxido de carbamida a 10\% na resistência mecânica, de tal forma que a média encontrada no grupo 1 , dentes não submetidos ao clareamento, foi de 6,5 $\mathrm{MPa}$, sendo a diferença estatisticamente significativa quando comparada ao grupo 2 e grupo 3 que apresentaram os valores de 10,2 MPa e 10,6 MPa,

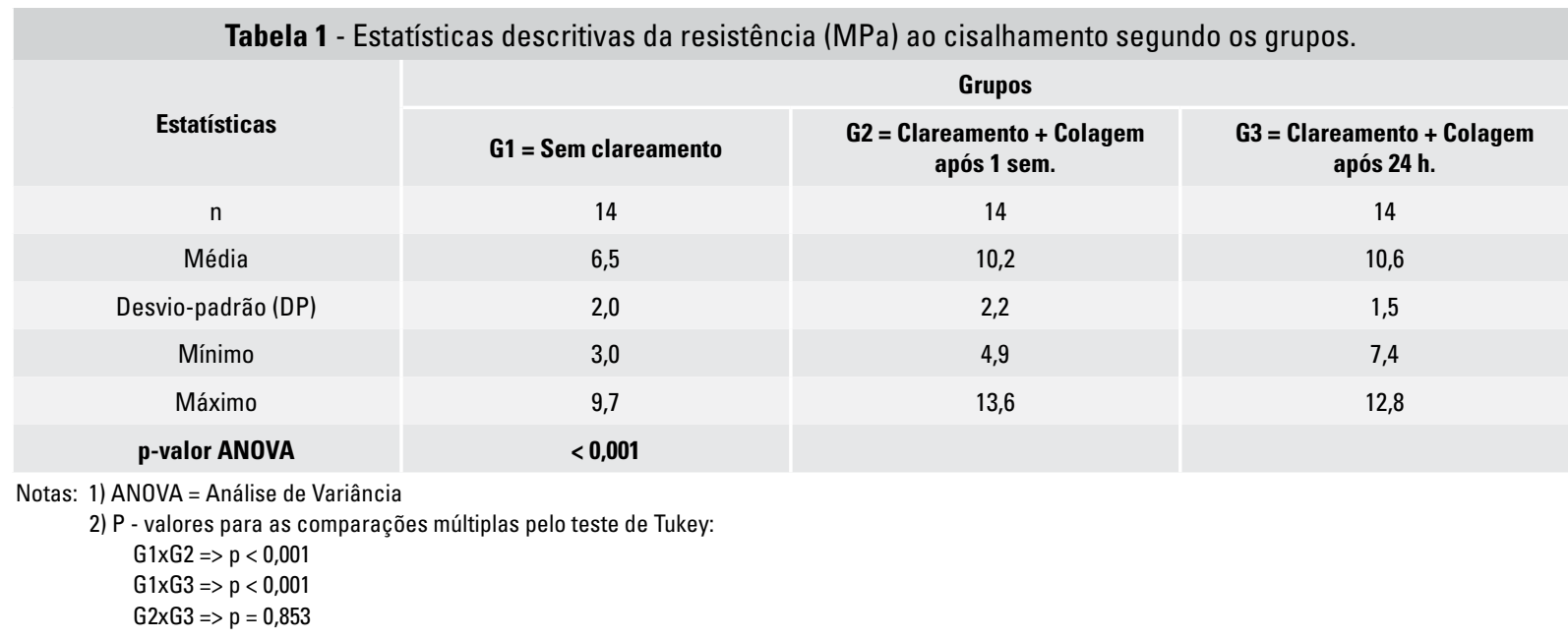


respectivamente, corroborando com os achados de Torneck, Titley, Smith e Adibfar ${ }^{11}$. A diferença entre o grupo 1 e os grupos 2 e 3 é apresentada no gráfico 1 que expressa a resistência (MPa) ao cisalhamento segundo os grupos e evidencia a discrepância entre o grupo sem clareamento (Gl) e os grupos que foram submetidos ao clareamento (G2 e G3). Esses achados discordam dos resultados encontrados por Murchison, Charlton, Moore ${ }^{9}$, Bishara, Sulieman e Olson², que afirmam não haver interferência do clareamento na resistência adesiva do esmalte dentário, assim como também, diferem dos achados relatados por Cvitko, Denehy, Swift ${ }^{3}$; Stokes, Hood, Dhariwal et al..$^{10}$; Titley, Torneck, Ruse ${ }^{12}$; Garcia-Godoy, Dodge, Donohoue et al. ${ }^{4}$; Titley, Torneck, Ruse et al. ${ }^{13}$; Miles, Pontier e Bahirael et al. ${ }^{8}$, que afirmaram que o clareamento reduz significativamente a resistência mecânica da colagem de braquetes.

A influência do tempo decorrido do final do processo de clareamento do esmalte até a execução da colagem, foi investigada com intuito de esclarecer questionamentos a respeito do melhor momento em se montar o aparelho ortodôntico após o tratamento clareador. Os valores médios da resistência ao cisalhamento dos grupos 2 e 3 apresentaram-se bem próximos, 10,2 MPa e 10,6
$\mathrm{MPa}$, respectivamente, não apresentando diferenças estatisticamente significativas, conforme mostra a tabela 1. Miles, Pontier, Bahirael et al. ${ }^{8}$ concluiram que dentes submetidos ao clareamento, e nos quais é realizada a colagem somente 1 semana após o tratamento cosmético e imersos em água durante esse período, retornam a apresentar a mesma resistência mecânica do grupo controle que não foi submetido a tratamento, achado esse que difere do encontrado neste trabalho, já que neste trabalho no grupo 2 a colagem foi realizada somente 1 semana após a finalização do clareamento e os mesmos também foram estocados em água, sendo que os valores médios evidenciaram diferença estatisticamente significante entre o grupo 1 e 2.

\section{CONCLUSÃO}

Os resultados deste trabalho permitem concluir:

1) $O$ agente clareador aumenta significativamente a resistência mecânica da colagem de braquetes ortodônticos.

2) O tempo decorrido do final do tratamento clareador até a colagem do braquete ortodôntico não interferiu na resistência mecânica da colagem quando a mesma foi realizada 24 horas ou 1 semana após o clareamento.

Influence of $10 \%$ carbamide peroxide gel on the shear bond strength of orthodontic brackets

\begin{abstract}
The purpose of this in vitro study was to determine the influence of $10 \%$ carbamide peroxide gel on the shear bond strength of orthodontic brackets. Three group were studied: G1 (without bleaching), G2 (bleaching and bonding after 1 week) and G3 (bleaching and bonding after 24h). The shear test was conduced in a Emic testing machine with a crosshead speed of $0,5 \mathrm{~mm} / \mathrm{min}$. The shear bond strength was calculated for each tooth and expressed in $\mathrm{MPa}$. The results show enhance statistical significant $(p<0,001)$ on the shear bond strength after bleaching and encreased with the time interval between bleaching and bonding, significantily.
\end{abstract}

Key words: Dental bleaching. Carbamide peroxide. Bond strength. 


\section{REFERÊNCIAS}

1. BARATIERI, L. N.; MONTEIRO JÚNIOR; S.; ANDRADE, M. A. C. et al. Clareamento dental. 2. ed. São Paulo: Ed. Santos, 1993. p. 4-7.

2. BISHARA, S. E.; SULIEMAN, A. H.; OLSON, M. Effect of enamel bleaching on the bonding strength of orthodontic brackets. Am J Orthod Dentofacial Orthop, St. Louis, v. 104, no. 5, p. 444447, Nov. 1993.

3. CVITKO, E.; DENEHY, G. E.; SWIFT, E. J. JR.; PIRES, J. A. Bond strenght of composite resin to enamel bleached with carbamide peroxide. J Esthet Dent, Philadelphia, v. 3, no. 3, p. 100-102, May/June 1991

4. GARCIA-GODOY, F.; DODGE, W.W.; DONOHUE, M.; O'QUINN, J. A. Composite resin bond strenght after enamel bleaching. Oper Dent, Seattle, v. 18, no. 4, p. 144-147, July/Aug. 1993

5. GOLDSTEIN, R. E.; GARBER, D. A.; GOLDSTEIN, C. et al. Esthetic update: changing esthetic dental practice. J Am Dent Assoc, Chicago, v. 125, no. 11, p. 1447-1456, Nov. 1994

6. HAYWOOD, V. B.; LEECH, T.; HEYMANN, H. O. et al. Nighguard vital bleaching: Effects on enamel surface texture and difusion. Quintessence Int, Berlin, v. 21, no. 10, p. 801-814, Oct. 1990.

7. MATIS, B. A.; COCHRAN, M. A.; ECKERT, G. et al. The efficacy and safety of a $10 \%$ carbamide peroxide bleaching gel. Quintessence Int, Berlin, v. 29, no. 9, p. 555-563, Sept. 1998.

8. MILES, P. G.; PONTIER, J. P.; BAHIRAEI, D. et al. The effect of carbamide peroxide bleach on the tensile bond strength of ceramic brackets: an in vitro study. Am J Orthod Dentofacial Orthop, v. 105, no. 4, p. 371-375, Oct. 1994.

9. MURCHISON, D. F.; CHARLTON, D. G.; MOORE, B. K. Carbamide peroxide bleaching; effects on enamel surface hardness and bonding. Oper Dent, Seattle, v. 17, no. 5, p. 181-185, Set./Oct. 1992

10. STOKES, A. N.; HOOD, J. A.; DHARIWAL, D.; PATEL, K. Effect of peroxide bleaches on resin-enamel bonds. Quintessence Int Berlin, v. 23, no. 11, p. 769-771, Nov. 1992

11. TORNECK, C. D. TYTLEY, K. C. SMITH, D. O : ADIBFAR, A Effect of water leaching the adhesion of composite resin to bleached and unbleached bovine enamel. J Endod, Chicago, v. 17 no. 4, p. 156-160, Apr. 1991

12. TYTLEY, K. C.; TORNECK, C. D.; RUSE, N. D. The effect of carbamide-peroxide gel on the shear bond strength of a microfil resin to bovine enamel. J Dent Res, Chicago, v. 71, no.1, p. 20-24, Jan. 1992

13. TYTLEY, K. C.; TORNECK, C. D.; RUSE, N. D.; KRMEC, D. Adhesion of a resin composite to bleached and unbleached huma enamel. J Endod, Chicago, v. 19, no. 3, p. 112-115, Mar. 1993.

14. TYTLEY, K. C.; TORNECK, C. D.; SMITH, D. C. The effect of concentrated hidrogen peroxide solutions on the surface morphology of human tooth enamel. J Endod, Chicago, v. 14, no. 2, p 69-74, Feb. 1988.

\section{Endereço para correspondência}

Edgard Norões Rodrigues da Matta

Faculdade de Odontologia da UFRJ - Disciplina de Ortodontia

Av. Brigadeiro Trompowsky, s/n - Cidade Universitária

CEP: 21941-590

Ilha do Fundão - RJ

E-mail: edgard@ortodontia.ufrj.br 